THURSDAY, FEBRUARY $2,1888$.

\section{THE COMPOSITION OF WATER.}

$\mathrm{D}$ UMAS, in his well-known memoir on the gravimetric composition of water, which every student is taught, and rightly so, to regard as one of the classics of chemistry, states that of all analyses presented to a chemist that of water is the one which offers the greatest uncertainty. Critics of a certain type may possibly take exception to the literal accuracy of this remark. No one, however, will gainsay the statement that, in view of the momentous issues which depend upon our knowledge of the composition of water, this knowledge is not by any means so exact as the state of contemporary science demands. It is, of course, not merely the question of the quantitative composition of water, but the far more important matter of the relative values of the atomic weights of hydrogen and oxygen. Of all stoïchiometrical constants required by chemists nowadays, those of hydrogen and oxygen are infinitely the most important. Every chemist knows what is dependent on these ratios, and he knows too that the difficulties which their direct determination involves are well-nigh insuperable.

All the discussions within recent years on the validity of Prout's law have tended to show that so far as experimental work is concerned, the question may now be said to hang upon these particular values. It is not too niuch to say that, if any chemist could succeed in showing by irrefragable experimental evidence that the atomic weight of oxygen was exactly sixteen times that of hydrogen, he would in the present state of scientific opinion at once succeed in inducing his brethren to accept Prout's law and all its far-reaching consequences as articles of their chemical creed.

It may be worth while to examine very briefly the nature of the ground upon which the present accepted values for the relative atomic weights of hydrogen and oxygen are based. It will be generally conceded that the evidence upon which chemists have almost exclusively relied is that afforded by Dumas' gravimetric analysis of water, and by Regnault's determination of the specific gravities of oxygen and hydrogen.

Dumas' work was published in 1843. His method was identical in principle with that employed by Dulong and Berzelius for the same purpose, and consisted, as is well known, in heating copper oxide with an unknown weight of hydrogen, and determining (I) the loss of weight suffered by the oxide, and (2) the weight of the water formed. The decrease in weight of the copper oxide was assumed to represent the weight of the oxygen evolved, and the difference between this weight and that of the water formed was held to be the amount of hydrogen which had combined with that of the oxygen.

In all, nineteen experiments were completed, in which quantities of water varying from about fifteen to eighty-six grammes were formed. Treating the results in the manner adopted by Meyer and Seubert-that is, in accordance with the equation

$$
x=\frac{b_{1}+b_{2}+b_{3}+\ldots++b_{n}}{a_{1}+a_{2}+a_{3}+\ldots \cdot+a_{n}}=\frac{[b]}{[a]},
$$

VoL. XXXVII -No. 953 . in which $a=$ weight of oxygen used, and $b=$ weight of water formed-it follows that $[a]=840 \cdot 16$ grammes, and $[b]=945^{\circ} 44$ grammes, whence the ratios $\mathrm{H}: \mathrm{O}=\mathrm{I}: 15^{\circ} 96$.

When, however, we come to examine more nearly the details of the method of determination, we find that these ratios are certainly affected by errors of which the magnitude cannot be even approximately known. In the first place, the sulphuric acid solution employed to generate the hydrogen must have contained dissolved air, the effect of which would be to lower the ratio of the oxygen. This fact was not indeed unnoticed by Dumas, but its effect could not be estimated with any certainty. Moreover, it seems almost impossible to prepare hydrogen from zinc and sulphuric acid without the formation of more or less sulphur dioxide, the last traces of which can only be removed by prolonged exposure to potash solution. Copper is one of the few metals that have the power of forming a hydride, and although this hydride, like the palladium hydride, is more or less readily decomposed by heat, the affinity of hydrogen for copper may be still traceable even at moderately high temperatures. Melsens, working in Dumas' laboratory, found that the reduced copper did actually retain hydrogen, and in amount varying with the temperature to which it had been heated. The weight of the condensed water must have been increased, as Berzelius pointed out, by the air which it eventually dissolved. Now the effect of all these errors would be to lower the value for the atomic weight of oxygen. Of course there may have been errors working in the opposite direction of which we know nothing, but it is reasonably certain that the net result of the constant errors, so far as these can be ascertained, is to give too small a value for oxygen. Above all, there are the fortuitous errors, such as those caused by differences in the power of surface-condensation of the vessels employed; errors of weighing and of reduction to a standard atmosphere, \&c.; which, although theoretically allowed for and eliminated by a sufficiently frequent repetition of the experiments, may, on the whole, tend to operate in a given direction. Lastly, there is a source of error of the same order in a circumstance which, as there is a certain touch of pathos in them, may be stated in Dumas' own words :-

"Il faut même ajouter que la durée nécessaire de ces opérations, en m'obligeant à prolonger le travail fort avant dans la nuit, en plaçant les pesées vers deux ou trois heures du matin dans la plupart des cas, constitue une cause d'erreur réelle. Je n'oserais pas assurer que de telles pesées méritent autant de confiance que si elles avaient été exécutées dans des circonstances plus favorables et par une observateur moins accable de la fatigue inévitable après quinze ou vingt heures d'attention soutenue."

There is, above and beyond all, a fundamental flaw in the principle of the method, of which Dumas himself was fully conscious. After having declared that of all analyses presented to a chemist water is the one which offers the greatest uncertainty, he goes on to state to what this uncertainty is due:-

"En effet, I partie [d'hydrogène se combine avec 8 parties d'axygène pour former de l'eau, et rien ne serait 
plus exact que l'analyse de l'eau, si l'on pouvait peser l'hydrogène et peser l'eau qui proviendrait de sa combustion. Mais l'expérience n'est pas possible sous cette forme. Nous sommes obligés de peser l'eau formée, et l'oxygène qui a servi à lid produire, pour en déduire, par différence, le poids de l'hydrogène qui en fait partie. Ainsi, une erreur de $\mathrm{r} / 900$ sur le poids de l'eau, ou de $1 / 800$ sur le poids de l'oxygène, affecte d'une quantité égale à $\mathrm{I} / 90$ ou à $\mathrm{I} / 80$ le poids de l'hydrogène. Que ces erreurs étant dans le même sens viennent à s'ajouter, et l'on aura des erreurs qui iront à $\mathrm{I} / 40 . "$

Let us now turn our attention to the evidence afforded by Regnault's determinations of the densities of oxygen and hydrogen. Prof. Le Conte has detected some slight numerical errors in Regnault's reductions (Phil. Mag. [4] 27-29), and when the necessary corrections are made it follows that the density of oxygen is 1.105612 , and that of hydrogen 0.069269 ; whence, on the assumption of Avogadro's law, we have the ratio $\mathrm{O}: H=15^{\circ} 96 \mathrm{I}: \mathrm{I}$. This result is in such striking agreement with Dumas' value that it is generally held to afford the strongest corroboration of it. The number given for oxygen is probably among the most accurate of Regnault's determinations of gaseous densities; the subsequent results of Von Jolly, which are alone comparable in character with those of Regnault, when reduced to the geographical position of Regnault's laboratory have not materially altered the value. The number given for hydrogen is certainly not entitled to the same degree of confidence. Indeed, it has been stated that Regnault was himself of this opinion, on account of the great difficulty of procuring hydrogen free from air. It is hardly necessary to point out that even an extremely minute admixture of air would tend to lower the relative value of the atomic weight of oxygen. Moreover, the hydrogen in the course of its preparation must have been saturated with moisture ; and although, of course, all precautions at that time known were taken to dry the gas, it is quite certain that it could not have been absolutely free from traces of water. The experiments of Dixon have shown how extremely difficult it is to dry a gas perfectly, and it is now recognized that the ordinary methods of desiccation still leave appreciable traces of moisture in it. The effect of this moisture in the case of hydrogen would be to increase its density, whereas in the case of the oxygen it would tend to decrease it. On the other hand, oxygen and hydrogen when measured under the standard conditions of temperature and pressure are not, strictly speaking, under exactly comparable conditions, and the assumption of the validity of Avogadro's law is not mathematically correct.

Within recent years the question of the composition of water has been again attacked, and with a fuller knowledge of the various sources of error which the progress of science has shown to be present in the older methods. Julius Thomsen found that I litre of dry hydrogen, measured under standard conditions of temperature and pressure, when burnt with oxygen gave, as the mean of eight concordant experiments, 0.804I grammes of water. Accordingly, 2 litres of hydrogen, on combining with oxygen, would give I 6082 grammes of water. Assuming the validity of Gay-Lussac's law, and using Regnault's values for the weights of the gases at standard temperature and pressure, the calculated weight becomes-

$$
\begin{aligned}
2 \text { litres hydrogen } & =0.179 \mathrm{r} \text { grammes } \\
\text { I litre oxygen } & =1.4298, " \\
\text { water } & =\overline{\mathrm{I} .6089},,
\end{aligned}
$$

The difference is $0^{\prime 7}$ milligramme. But the question may be immediately asked, "Is Gay-Lussac's law actually valid?" The work of Regnault and Amagat on the relation of volumes of gases to heat and pressure indicates that, as ordinarily stated, it cannot be absolutely valid. Dr. A. Scott has recently put the question to the test of experiment, and, from a long series of trials in which large volumes of gases were caused to combine, he finds that the most probable ratio is I 994 : I (Proc. Roy. Soc., I887, 398). Taking Regnault's data as before, we have-

$$
\begin{aligned}
\text { I'994 litres hydrogen } & =0.1876 \text { gramme } \\
\text { I litre oxygen } & =1.4298,, \\
\text { water } & =\mathbf{I} \cdot 6084,
\end{aligned}
$$

which differs only by $0^{\prime} 2$ milligramme from Thomsen's result.

Now, from Regnault's densities of oxygen and hydrogen, as recalculated by Prof. Le Conte, it follows that the weights of equal volumes of the gases are as I : 15.9611 , which, on the basis of Dr. Scott's ratio for the combining volumes, gives-

$$
\mathrm{O}=16.009
$$

Prof. J. P. Cooke and Mr. T. W. Richards, of Harvard College, have recently presented us with a further contribution to the subject (Proc. Amer. Acad. of Arts and Sciences, xxiii. 149), which merits very special attention, not only on account of the intrinsic excellence of the experimental work of which it is an account, but also because it is here attempted to obviate certain of the sources of error which have already been pointed out as inherent in Dumas' method. The method adopted by the American chemists was to pass a known weight of hydrogen over heated copper oxide and to weigh the amount of water formed. It will be seen that the essential feature in this method is that the weight of the hydrogen is known whilst that of the oxygen is obtained by difference; in contradistinction to the method of Dumas, where the weight of the oxygen was known and that of the hydrogen found by difference. The preparation of this hydrogen and the determination of its weight were, however, problems which required the highest manipulative skill. Obviously, everything depends upon the purity of the hydrogen. A glass globe of about 5 litres capacity and weighing about 570 grammes was so provided with stopcocks that it could be evacutated by the air-pump. The vacuous globe was weighed against a similar globe, in the manner already adopted by Regnault, filled with hydrogen, and its weight again determined. The weight of hydrogen taken was about $0^{\circ} 42$ gramme. The hydrogen was then driven over the heated copper oxide by a current of dry air, and the water formed collected partly in a weighed tube, and partly by means of sulphuric acid and phosphoric oxide. The hydrogen was obtained by three different methods: (I) by the action of sulphuric acid 
upon zinc; (2) by means of caustic potash and aluminium; and (3) by electrolysis. In all, sixteen experiments are given. The results are stated in the following table :-

\begin{tabular}{|c|c|c|c|c|c|c|}
\hline \multirow{2}{*}{ 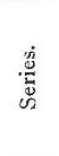 } & \multirow{2}{*}{ 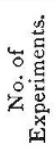 } & \multirow{2}{*}{ 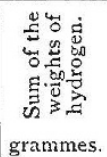 } & \multirow{2}{*}{ 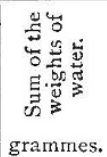 } & \multicolumn{3}{|c|}{ Atomic weight of oxysen. } \\
\hline & & & & $\max$ & min. & $\begin{array}{l}\text { Calc, from } \\
\text { sums. }\end{array}$ \\
\hline I. & 5 & 2.0876 & I 8.7406 & 159 & & \\
\hline II. & 5 & 2.080 .3 & 18.6740 & 15.962 & 15.942 & 15.953 \\
\hline III. & 6 & $2.535^{\circ}$ & $22.754 \mathrm{r}$ & 15.967 & 15.937 & 15952 \\
\hline
\end{tabular}

The final mean is $\mathrm{O}=\mathrm{r} \quad 0^{\circ} \mathrm{00} \mathrm{I} 7$.

This very bald account does but scanty justice to the beauty and simplicity of the methods adopted by Prof. Cooke and Mr. Richards, and to the manipulative skill and patience with which they carried them out. With respect to the bearing of their result on Prout's hypothesis, the question seems to them to narrow itself to this point: Is the hydrogen they have made use of the typical hydrogen element? They are inclined to believe that the theoretical question in regard to Prout's law has been settled so far as analytical work can solve the problem. On this point, however, we are at issue with them. That statement implies a finality about our present quantitative methods which we have no right to assume. It implies, too, that the methods employed by the authors have yielded as close an approximation to the typical element as we are ever likely to obtain. Their method in principle no cloubt removes one fundamental objection to Dumas' plan of work, considered as an experimental process, but it by no means removes all the sources of error, and anybody who will patiently sift out these sources and seek to appreciate their net effect must admit that the ultimate tendency is to apparently lower the relative value of the atomic weight of oxygen.

If we have regard to this fact, and if we consider too what we may call the volumetric evidence, as given above, it seems premature to assume that the ultimate question has actually been narrowed down to the point to which Prof. Cooke and Mr. Richards are disposed to conclude that they have brought it.

T. E. THORPE.

PHYSICAL GEOGRAPHY OF THE SEA.

Handbuch der Ozeanographie. Von Dr. Georg von Boguslawski und Prof. Dr. Otto Krümmel. Two Vols. (Stuttgart: Engelhorn, 1884-87.)

THESE volumes belong to a series of geographical hand-books-each written by an acknowledged master of the subject--brought out on a uniform plan, under the editorship of Prof. Dr. F. Ratzel, by the well-known Stuttgart publishing firm of Engelhorn.

Dr. Ratzel's own volume on Anthropogeography, Dr. Hann's on Climatology, and Dr. Heim's on Glaciers have already appeared; and now, under the somewhat novel name of "Oceanography," the physical geography of the sea has been exhaustively treated. The editor has divided the subject into two parts, and given each to a specialist. In Volume I., Prof. Dr. G. von Bogusslawski, of the Hydrographical Department of the German Admiralty, treats of the distribution, physical condition, and chemical composition of sea-water ; while in Volume II., Dr. Otto Krümmel, Professor of Geography in the University of Kiel, discourses on the motions of the ocean. Each part is complete in itself, but the index to both is given only in the second volume.

It is somewhat difficult to give an idea of the multifarious contents of this exhaustive treatise. In Volume I., Dr. Boguslawski begins with an account of the shape and area of the different oceans, and then naturally describes successively the physical character of their various coast-lines, and the depths of the sea all over the world. But we must remark on the poverty of illustration and the absence of maps which characterize this and so many other first-rate German books. Here we have actually no map, however rough, to show graphically the depth of the oceans. The unfortunate reader who wants to get his information as easily and quickly as possible has first to read through about 100 pages of closely-printed type, and then to try and picture to himself the relief of the floor of the sea.

After discussing ocean depths, the author devotes a short chapter to the chemical composition of salt water ; and then a somewhat longer space to the density or specific gravity of the sea. Colour and transparency are next discussed, and the last 200 pages are occupied with what is called maritime meteorology.

Of this space only thirty-four pages are devoted to wind and storms, and very rightly, as these subjects would require a special volume for their proper treatment. The remainder is occupied with a minute account of the temperature of the ocean, both on $t$ ie surface and at various depths; and with a notice of the distribution of ice in high latitudes. Here too, the value of the admirable text is greatly diminished by the absence of maps.

So far no mathematics have been required, but it is impossible to treat of the motions of the sea without algebraical formulæ. Dr. Krümmel, however, uses great judgment in only giving the formulæ of motion, which only involve simple algebra, and not the investigation of the formula, that would require much higher analysis.

In the second volume he begins with the consideration of waves. The theory of wave-motion, both in deep and shallow water, he gives first, mostly following Airy; while experimental illustrations, and observations on the actual length, height, and speed of waves follow next. Breakers and rollers are then discussed, together with their influence on the abrasion of coast-lines. Earthquake and volcanic waves are illustrated by a self-recorded tidal trace from South Georgia, which will be new to English readers; and the section ends with a capital account of stationary waves, sêches, and of the curious tidal phenomena in the Straits of Euripus, which so puzzled the ancient Greeks.

The author then turns to tides, dealing mostly with the theories of Laplace, Whewell, Ferrel, Airy, Thomson, \&c., but very wisely ending with a chapter on "unsolved problems." The difficult subject of the vertical circulation of the ocean is next discussed, and an admirable account given of the cold aufreibwasser-up-rubbed water-of tropical weather coasts. This uneuphonious term is applied to the cold water that is found 